\title{
Renal complications of lipodystrophy: A closer look at the natural history of kidney disease
}

\section{Baris Akinci $^{1}$ (D) | Sadiye Mehtat Unlu ${ }^{2}$ | Ali Celik ${ }^{3}$ | Ilgin Yildirim Simsir ${ }^{4}$ | \\ Sait Sen ${ }^{5}$ | Banu Nur ${ }^{6}$ | Fatma Ela Keskin ${ }^{7}$ | Basak Ozgen Saydam ${ }^{1}$ (D) | \\ Nilufer Kutbay Ozdemir ${ }^{8}$ | Banu Sarer Yurekli ${ }^{4}$ (D) | Bekir Ugur Ergur ${ }^{9}$ |}

Melda Sonmez $^{10}$ | Tahir Atik ${ }^{11}$ | Atakan Arslan ${ }^{12}$ | Tevfik Demir ${ }^{1}$ | Canan Altay ${ }^{12}$ |

Ulku Aybuke Tunc $^{13}$ | Tugba Arkan ${ }^{14}$ | Ramazan Gen ${ }^{15}$ | Erdal Eren ${ }^{16}$ | Gulcin Akinci ${ }^{17}$ |

Aslihan Arasli Yilmaz ${ }^{18}$ | Habib Bilen ${ }^{19}$ | Samim Ozen ${ }^{20}$ | Aygul Celtik ${ }^{21}$ | Senay Savas

Erdeve $^{18} \mid$ Semra Cetinkaya $^{18} \mid$ Huseyin Onay $^{11}$ | Sulen Sarioglu ${ }^{2}$ | Elif Arioglu Oral ${ }^{22}$

${ }^{1}$ Division of Endocrinology, Department of Internal Medicine, Dokuz Eylul University, Izmir, Turkey

${ }^{2}$ Department of Pathology, Dokuz Eylul University, Izmir, Turkey

${ }^{3}$ Division of Nephrology, Department of Internal Medicine, Dokuz Eylul University, Izmir, Turkey

${ }^{4}$ Division of Endocrinology, Department of Internal Medicine, Ege University, Izmir, Turkey

${ }^{5}$ Department of Pathology, Ege University, Izmir, Turkey

${ }^{6}$ Division of Pediatric Genetics, Department of Pediatrics, Akdeniz University, Antalya, Turkey

${ }^{7}$ Division of Endocrinology, Department of Internal Medicine, Cerrahpasa Faculty of Medicine, Istanbul University, Istanbul, Turkey

${ }^{8}$ Division of Endocrinology, Diyarbakir Training Hospital, Diyarbakir, Turkey

${ }^{9}$ Department of Histology, Dokuz Eylul University, Izmir, Turkey

${ }^{10}$ Koc University School of Medicine, Istanbul, Turkey

${ }^{11}$ Division of Pediatric Genetics, Department of Pediatrics, Ege University, Izmir, Turkey

${ }^{12}$ Department of Radiology, Dokuz Eylul University, Izmir, Turkey

${ }^{13}$ Division of Endocrinology, Karabuk State Hospital, Karabuk, Turkey

${ }^{14}$ Division of Endocrinology, Kocaeli Training Hospital, Kocaeli, Turkey

${ }^{15}$ Division of Endocrinology, Department of Internal Medicine, Mersin University, Mersin, Turkey

${ }^{16}$ Division of Pediatric Endocrinology, Department of Pediatrics, Uludag University, Bursa, Turkey

${ }^{17}$ Division of Pediatric Neurology, Dr. Behcet Uz Children's Hospital, Izmir, Turkey

${ }^{18}$ Division of Pediatric Endocrinology, Dr. Sami Ulus Obstetrics and Gynecology, Children's Health and Disease Training and Research Hospital, Ankara, Turkey

${ }^{19}$ Division of Endocrinology, Department of Internal Medicine, Ataturk University, Erzurum, Turkey

${ }^{20}$ Division of Pediatric Endocrinology, Department of Pediatrics, Ege University, Izmir, Turkey

${ }^{21}$ Division of Nephrology, Department of Internal Medicine, Ege University, Izmir, Turkey

${ }^{22}$ Division of Endocrinology and Metabolism, Brehm Center for Diabetes Department of Internal Medicine, University of Michigan, Ann Arbor, MI, USA

Correspondence

Baris Akinci, Division of Endocrinology,

Dokuz Eylul University, Izmir, Turkey.

Email: barisakincimd@gmail.com

Funding information

$\mathrm{NIH}$, Grant/Award Number: RO-1DK88114

\section{Summary}

Objectives: Lipodystrophy syndromes are a group of heterogeneous disorders characterized by adipose tissue loss. Proteinuria is a remarkable finding in previous reports.

Study design: In this multicentre study, prospective follow-up data were collected from 103 subjects with non-HIV-associated lipodystrophy registered in the Turkish 
Lipodystrophy Study Group database to study renal complications in treatment naïve patients with lipodystrophy.

Methods: Main outcome measures included ascertainment of chronic kidney disease (CKD) by studying the level of proteinuria and the estimated glomerular filtration rate (eGFR). Kidney volume was measured. Percutaneous renal biopsies were performed in 9 patients.

Results: Seventeen of 37 patients with generalized and 29 of 66 patients with partial lipodystrophy had CKD characterized by proteinuria, of those 12 progressed to renal failure subsequently. The onset of renal complications was significantly earlier in patients with generalized lipodystrophy. Patients with CKD were older and more insulin resistant and had worse metabolic control. Increased kidney volume was associated with poor metabolic control and suppressed leptin levels. Renal biopsies revealed thickening of glomerular basal membranes, mesangial matrix abnormalities, podocyte injury, focal segmental sclerosis, ischaemic changes and tubular abnormalities at various levels. Lipid vacuoles were visualized in electron microscopy images.

Conclusions: CKD is conspicuously frequent in patients with lipodystrophy which has an early onset. Renal involvement appears multifactorial. While poorly controlled diabetes caused by severe insulin resistance may drive the disease in some cases, inherent underlying genetic defects may also lead to cell autonomous mechanisms contributory to the pathogenesis of kidney disease.

\section{KEYWORDS}

chronic kidney disease, insulin resistance, lipodystrophy, proteinuria

\section{1 | INTRODUCTION}

Lipodystrophy syndromes are a group of heterogeneous disorders affecting adipose tissue differentiation or distribution as well as metabolism. Congenital generalized lipodystrophy (CGL) is a rare, mostly autosomal recessive disorder characterized by near total absence of the body adipose tissue. Several genes have been identified for CGL which includes 1-acylglycerol-3-phosphate O-acyltransferase 2 (AGPAT2), Berardinelli-Seip congenital lipodystrophy 2 (BSCL2), caveolin 1 (CAV1) and polymerase I and transcript release factor (PTRF). ${ }^{1}$ The lack of adipose tissue is selective in patients with partial lipodystrophy. Mutations in several genes have been identified in different subtypes of familial partial lipodystrophy (FPLD), most of which are inherited as an autosomal dominant trait. The most common subtype of FPLD, FPLD2 is caused by heterozygous mutations in the lamin A/C (LMNA) gene. ${ }^{2}$ In acquired lipodystrophy syndromes, patients develop adipose tissue loss at some point during life. ${ }^{3}$

The kidney is one of the organs affected in lipodystrophy. The aetiologic basis of renal complications associated with lipodystrophy has remained largely unknown; however, it is usually characterized by proteinuria. ${ }^{4}$ Javor et $\mathrm{al}^{5}$ reported that proteinuria was strikingly frequent in patients with generalized lipodystrophy who were being treated with metreleptin. Renal involvement has also been reported in the course of FPLD. ${ }^{6-8}$ Renal involvement in acquired partial lipodystrophy (APL) has been associated with abnormalities of the alternative complement pathway, which is C3-nephritic factor associated mesangiocapillary glomerulonephritis (C3-MPGN). ${ }^{3}$

Considering that novel treatments are in progress in lipodystrophy, it is essential to document the natural history of the disease and the disease burden in patients with lipodystrophy who are naïve to these lipodystrophy specific novel treatments. In this multicentre observational study, we specifically focused on renal complications. We studied 103 novel drug naïve patients with various forms of lipodystrophy for renal abnormalities who were registered in the Turkish Lipodystrophy Study Group (TuLip) national registry. To better understand the pathogenesis of renal involvement in patients with lipodystrophy, we further investigated the renal biopsy samples of 9 patients.

\section{MATERIALS AND METHODS}

\section{1 | Patients}

Initially, 109 patients non-HIV associated lipodystrophy from the TuLip registry were included in this study. None of the patients received metreleptin or any other drug in development for lipodystrophy at the time of data collection. Patients with specific syndromes such as mandibuloacral dysplasia, Short 
syndrome and Candle/JMP syndrome were excluded from the study. Five patients were not included in the analysis as they either did not have a regular follow-up for renal complications or refused to attend the data collection visits. Another patient with partial lipodystrophy was excluded as he was diagnosed with systemic lupus erythematosus, and lupus nephritis was detected on the renal biopsy. The study was approved by the Dokuz Eylul University Ethics Review Panel. Written informed consent was obtained.

\section{2 | Diagnosis and classification of lipodystrophy}

CGL was diagnosed based on generalized adipose tissue loss that was remarkable at birth or noticed at early stages of life. Acquired generalized lipodystrophy (AGL) was diagnosed based on the development of generalized adipose tissue loss later on in childhood or later. FPLD was diagnosed based on partial adipose tissue loss in selected areas. APL was diagnosed based on acquired adipose tissue loss characteristically starting at the face, progressing in a cephalocaudal fashion to the trunk and upper extremities. Adipose tissue distribution was also assessed by whole-body magnetic resonance imaging (WB MRI; Gyroscan Intera, release 8.1; Philips Medical Systems, Best, the Netherlands) with a 6-multichannel body coil. Mutation analysis of the genes LMNA, LMNB2, PPARG, AGPAT2, BSCL2, CAV1, PTRF, PLIN1, AKT2, LIPE, ADRA2A, ZMPSTE24 and CIDEC was carried out by direct automated DNA sequencing from the patients' genomic DNA, based on the clinical features. Sequencing was performed with Miseq V2 chemistry on MiSeq instrument (Illumina, California, USA).

\subsection{Data collection and analysis}

The prospective follow-up data were collected by the investigators at several centres of the TuLip. After reviewing the registry retrospectively, a final visit was scheduled to update the clinical findings. Blood pressure was measured using a sphygmomanometer in the sitting position after 5 -minute rest. For the adult age group, patients on antihypertensive treatment and those with resting blood pressure higher than 140/90 $\mathrm{mm} \mathrm{Hg}$ were considered as hypertensive. For the paediatric age group, adjusted blood pressure for age, height and gender higher than 95th percentile was considered as having hypertension.

Patients underwent a detailed physical examination, full biochemistry and urinalysis for protein content. Biochemical tests were studied by standardized methods with appropriate quality control and quality assurance procedures. Direct low-density lipoprotein (LDL) cholesterol measurement was performed. Leptin and adiponectin levels were measured with enzyme-linked immunosorbent assay (ELISA) according to the manufacturer's instructions (Boster, Pleasanton, CA, USA). Diabetes was defined according to the recommendations of American Diabetes Association (ADA). ${ }^{9}$ Lipid levels were classified according to the
National Cholesterol Education Program Adult Treatment Panel (NCEP ATP III) guidelines. ${ }^{10}$ Age-specific thresholds were used for children and adolescents. ${ }^{11}$

We defined chronic kidney disease (CKD) as abnormalities of kidney structure or function, which persisted for at least 3 months. Estimated GFR (eGFR) was calculated using the CKDEPI formula. ${ }^{12}$ Bedside Schwartz formula was used for children. ${ }^{13}$ eGFR and proteinuria were classified according to the Kidney Disease Outcomes Quality Initiative (KDOQI) and updated guideline of the Kidney Disease Improving Global Outcomes (KDIGO). ${ }^{14}$ The screening strategy for albuminuria/proteinuria consisted of urine dipstick test, spot urine protein/creatinine test, spot urine albumin/creatinine ratio and 24-hours urine collections. We were able to perform 24-hours urine collections in 100 of 103 patients. Positive dipstick test results were followed by a quantitative measurement. In adults ( $\geq 18$ years), urinary protein excretion of $\geq 150 \mathrm{mg} / \mathrm{d}$ was considered to be abnormal. Microalbuminuria (moderately increased albuminuria) was diagnosed from a 24hours urine collection (between 30 and $300 \mathrm{mg} / \mathrm{d}$ ) or from a spot sample $(30-300 \mathrm{mg} / \mathrm{g})$. Macroalbuminuria (severely increased albuminuria) was defined as an albumin excretion $\geq 300 \mathrm{mg} / \mathrm{d}$ or $\geq 300 \mathrm{mg} / \mathrm{g}$ on a spot specimen. Nephrotic range proteinuria was considered with a protein excretion of $3.5 \mathrm{~g}$ or more per day. Proteinuria in children was defined as greater than $100 \mathrm{mg} / \mathrm{m}^{2}$ urinary protein excreted per day. On a spot urine protein/creatinine test, proteinuria was defined as a ratio $>0.2$ in children older than 2 years of age or a ratio $>0.5$ in children aged between 6 and 24 months old. ${ }^{15}$ Nephrotic range proteinuria in children was defined as urinary protein excretion that exceeded $40 \mathrm{mg} / \mathrm{m}^{2} / \mathrm{h}$. We considered eGFR levels less than $60 \mathrm{~mL} / \mathrm{min} / 1.73 \mathrm{~m}^{2}$ as "decreased." In those with an eGFR $\geq 60 \mathrm{~mL} / \mathrm{min} / 1.73 \mathrm{~m}^{2}$, the presence of proteinuria established the diagnosis of CKD. End-stage renal disease (ESRD) was defined as having an eGFR less than $15 \mathrm{~mL} / \mathrm{min} / 1.73 \mathrm{~m}^{2}$. Elevated eGFR, which may reflect hyperfiltration, was considered if eGFR exceeded $130 \mathrm{~mL} / \mathrm{min} / 1.73 \mathrm{~m}^{2}$ in adults and $150 \mathrm{~mL} / \mathrm{min} / 1.73 \mathrm{~m}^{2}$ in children.

\section{4 | Measurement of kidney volumes}

Kidney morphology was studied on either ultrasound or MRI. Kidney volumes were measured on axial 3D GRE fat saturated T1 weighted MRI images (Achieva 1.5-T scanner, Philips Medical Systems, Best, the Netherlands) using Myrian software (IDS 2.0, Sectra AB, Sweden). The interpretation of the measurements was done as suggested by Cheong et al. ${ }^{16}$

\section{5 | Renal biopsy}

Percutaneous renal biopsies were performed in 9 patients. All patients had proteinuria and insulin resistant diabetes. Samples were stained with haematoxylin and eosin (HE), periodic acid-Schiff (PAS), periodic acid methenamine silver (PAM) stains and Congo-red in 2-3 micron sections. For immune deposits, each specimen was evaluated 
using antibodies against IgG, IgA, IgM, complement-3 (C3), complement-1q (C1q), kappa and lambda. Light microscopy, immunofluorescence and electron microscopy (EM) samples were read by three experienced pathologists.

\section{6 | Statistical analysis}

Statistical analysis was performed using Statistical Package of Social Science (SPSS Inc, Chicago, IL, USA), version 22 for
Windows. Student's $t$ test or Mann-Whitney $U$ test was used for comparison of scale parameters depending on distribution of variables. Categorical variables were compared by the chi-square test. The Spearman rank correlation coefficient was used to determine the relationship existing between continuous parameters. Partial correlations method was also used to measure the association between two variables while controlling the effect of additional variables. A P-value less than .05 was accepted as statistically significant.

\begin{tabular}{|c|c|c|c|}
\hline & $\begin{array}{l}\text { Generalized } \\
\text { lipodystrophy } \\
(n=37)\end{array}$ & $\begin{array}{l}\text { Familial partial } \\
\text { lipodystrophy } \\
(n=44)\end{array}$ & $P$ value \\
\hline Age (y) & $21 \pm 17$ & $38 \pm 15$ & $<.001$ \\
\hline Gender (F/M) & $21 / 16$ & $35 / 9$ & .032 \\
\hline BMI $\left(\mathrm{kg} / \mathrm{m}^{2}\right)$ & $19.05 \pm 3.25$ & $23.73 \pm 4.87$ & .003 \\
\hline Follow-up (mo) & $72 \pm 56$ & $57 \pm 84$ & .001 \\
\hline Diabetes/IGT & $20(54 \%) / 3(8 \%)$ & $31(71 \%) / 4(9 \%)$ & .221 \\
\hline Duration of diabetes (mo) & $151 \pm 97$ & $127 \pm 102$ & .403 \\
\hline Hypertension & $8(22 \%)$ & $17(39 \%)$ & .147 \\
\hline Glucose (mmol/L) & $8.01 \pm 4.39$ & $8.18 \pm 3.41$ & .851 \\
\hline HbA1c (\%) & $7.63 \pm 2.66$ & $7.38 \pm 1.94$ & .629 \\
\hline HOMA-IR score & $19.78 \pm 25.21$ & $9.88 \pm 9.32$ & .025 \\
\hline ALT (IU/L) & $56 \pm 55$ & $31 \pm 24$ & .048 \\
\hline GGT (IU/L) & $69 \pm 72$ & $53 \pm 59$ & .288 \\
\hline Total cholesterol (mmol/L) & $5 \pm 2.43$ & $5.66 \pm 1.98$ & .023 \\
\hline LDL cholesterol (mmol/L) & $2.34 \pm 1.13$ & $2.94 \pm 1.14$ & .084 \\
\hline HDL cholesterol (mmol/L) & $0.69 \pm 0.26$ & $0.89 \pm 0.28$ & .069 \\
\hline Triglyceride (mmol/L) & $7.78 \pm 9.42$ & $5.86 \pm 5.54$ & .258 \\
\hline Leptin (ng/mL) & $0.69 \pm 0.81$ & $6.47 \pm 6.54$ & $<.001$ \\
\hline Adiponectin ( $\mu \mathrm{g} / \mathrm{mL})$ & $5.33 \pm 7.98$ & $9.01 \pm 7.73$ & .033 \\
\hline Creatinine (mg/dL) & $1.1 \pm 1.5$ & $0.67 \pm 0.21$ & .067 \\
\hline C3 (mg/dL) & $137 \pm 28$ & $142 \pm 24$ & .469 \\
\hline CKD & $17(46 \%)$ & $23(52 \%)$ & .657 \\
\hline eGFR $\left(\mathrm{mL} / \mathrm{min} / 1.73 \mathrm{~m}^{2}\right)$ & $101 \pm 48$ & $109 \pm 23$ & .302 \\
\hline Urinary protein excretion (mg/d) & $1061 \pm 2982$ & $349 \pm 1084$ & .15 \\
\hline $\begin{array}{l}\text { The median age when CKD was first } \\
\text { detected }\end{array}$ & $23 \pm 14$ & $41 \pm 13$ & .007 \\
\hline $\begin{array}{l}\text { Macroalbuminuria (severely increased } \\
\text { albuminuria) }\end{array}$ & $13(35 \%)$ & 9 (21\%) & .21 \\
\hline Nephrotic range proteinuria & $5(14 \%)$ & $2(5 \%)$ & .237 \\
\hline eGFR $<60 \mathrm{~mL} / \mathrm{min} / 1.73 \mathrm{~m}^{2}$ & $8(22 \%)$ & $3(7 \%)$ & .1 \\
\hline ESRD, eGFR $<15 \mathrm{~mL} / \mathrm{min} / 1.73 \mathrm{~m}^{2}$ & $4(11 \%)$ & None & .04 \\
\hline
\end{tabular}

TABLE 1 Comparison of metabolic characteristics and renal parameters in patients with generalized lipodystrophy and familial partial lipodystrophy

ALT, alanine aminotransferase; BMI, body mass index; CKD, chronic kidney disease; C3, complement-3; eGFR, estimated glomerular filtration rate; ESRD, end-stage renal disease; F, Female; GGT, Gamma-glutamyl transferase; HOMA-IR, homeostatic model assessment; HDL, high-density lipoprotein; IGT, impaired glucose tolerance; LDL, low-density lipoprotein; M, male.

Data are presented as mean \pm standard deviation (SD).

Laboratory data shown are collected at the time of final visit. 


\section{3 | RESULTS}

The GL and PL cohorts were previously reported to describe mostly metabolic abnormalities. ${ }^{17,18}$ The age was heterogeneous ranging from 1 to 77 years. Thirty-seven patients had generalized lipodystrophy, of those 34 had CGL. CGL was caused by AGPAT2 mutations in 19 patients, BSCL2 mutations in 13 patients and PTRF mutations in 2 patients. Three patients had AGL. Sixty-six patients had partial lipodystrophy. Of those, 44 patients had FPLD. FPLD was caused by LMNA mutations in 21 patients, and PPARG mutations in 9 patients. We were not able to detect any pathogenic variant in 14 patients with FPLD in the genes sequenced. Twenty-two patients had APL.

Seventeen of 37 patients (46\%) with generalized lipodystrophy developed CKD characterized by proteinuria. CKD was present in all patients with CGL older than 26 years. The onset of renal complications was significantly earlier in patients with generalized lipodystrophy compared to those with FPLD (Table 1). Patients with generalized lipodystrophy were younger, and they were more insulin resistant although they had lower BMI. Hepatic steatosis was more severe (imaging data not shown here). Patients with generalized lipodystrophy had significantly lower levels of leptin and adiponectin (Table 1). Proteinuria was almost two times more common than retinopathy in patients with generalized lipodystrophy (Table S1). Proteinuria was at nephrotic range in 5 patients (14\%). Also, 10 additional patients (27\%) with generalized lipodystrophy had hyperfiltration. Eight patients (22\%) with generalized lipodystrophy had decreased eGFR. Of those, ESRD was detected in four patients (11\%). Three patients required haemodialysis. A patient with CGL was successfully treated with continuous ambulatory peritoneal dialysis (CAPD) for a year, and then she underwent a successful renal transplant.

Twenty-nine patients (44\%) with partial lipodystrophy developed CKD associated with proteinuria (Table S2). Three patients
(5\%) had proteinuria at nephrotic range. Five patients (8\%) had hyperfiltration. Four patients (6\%) with partial lipodystrophy had a progressive decrease in eGFR. Among them, a patient with APL developed ESRD, who was treated with haemodialysis. She received a successful renal transplant later. Serum C3 levels were suppressed in 12 of 22 (55\%) patients with APL, although no patient with FPLD had C3 levels below reference values (APL vs FPLD: $56 \pm 39 \mathrm{mg} / \mathrm{dL}$ vs $142 \pm 24 \mathrm{mg} / \mathrm{dL}, P<.001$ ). In the whole study group, patients who developed CKD were older and had more severe insulin resistance. Diabetes and lipids were poorly controlled. CKD was accompanied by hypertension in more than half of the patients (Table S3). There was only one patient with GL who developed CKD before the appearance of diabetes in the whole registry when patients with APL were excluded. However, 15 of 81 patients (19\%) developed CKD before or within 5 years of diabetes diagnosis, which was far earlier than general diabetes population. ${ }^{19}$

Kidney volumes were measured in 48 patients [15 with generalized lipodystrophy (14 CGL and $1 \mathrm{AGL}$ ), and 33 with partial lipodystrophy (25 FPLD and 8 APL)] on MRI. Nephromegaly was observed in 26 patients (54.2\%), of those 10 had CGL, 1 AGL, 13 FPLD and 2 APL. Kidney volumes were significantly elevated in patients generalized lipodystrophy compared to those with partial lipodystrophy $\left(312 \pm 116 \mathrm{~cm}^{3}\right.$ vs $223 \pm 48 \mathrm{~cm}^{3}, P=.012$ for the left kidney; $285 \pm 94 \mathrm{~cm}^{3}$ vs $216 \pm 49 \mathrm{~cm}^{3}, P=.016$ for the right kidney). Kidney volumes were found to be positively correlated with fasting glucose $(r=.602, P<.001$ for the left kidney, Figure $1 \mathrm{~A} ; r=.499, P=.002$ for the right kidney, Figure 1B), HOMA-IR score $(r=.435, P=.007$ for the left kidney, Figure $1 \mathrm{C} ; r=.349, P=.034$ for the right kidney, Figure 1D) and HbA1c ( $r=.75, P<.001$ for the left kidney; Figure 1E, $r=.693, P<.001$ for the right kidney, Figure $1 F$ ); and negatively correlated with leptin levels $[r=-.295, P=.076$ (not statistically significant) for the left kidney; Figure $1 G, r=-.385, P=.019$ for the right kidney, Fig. $1 \mathrm{H}$ ], when the data were controlled for age, gender, BMI and eGFR.
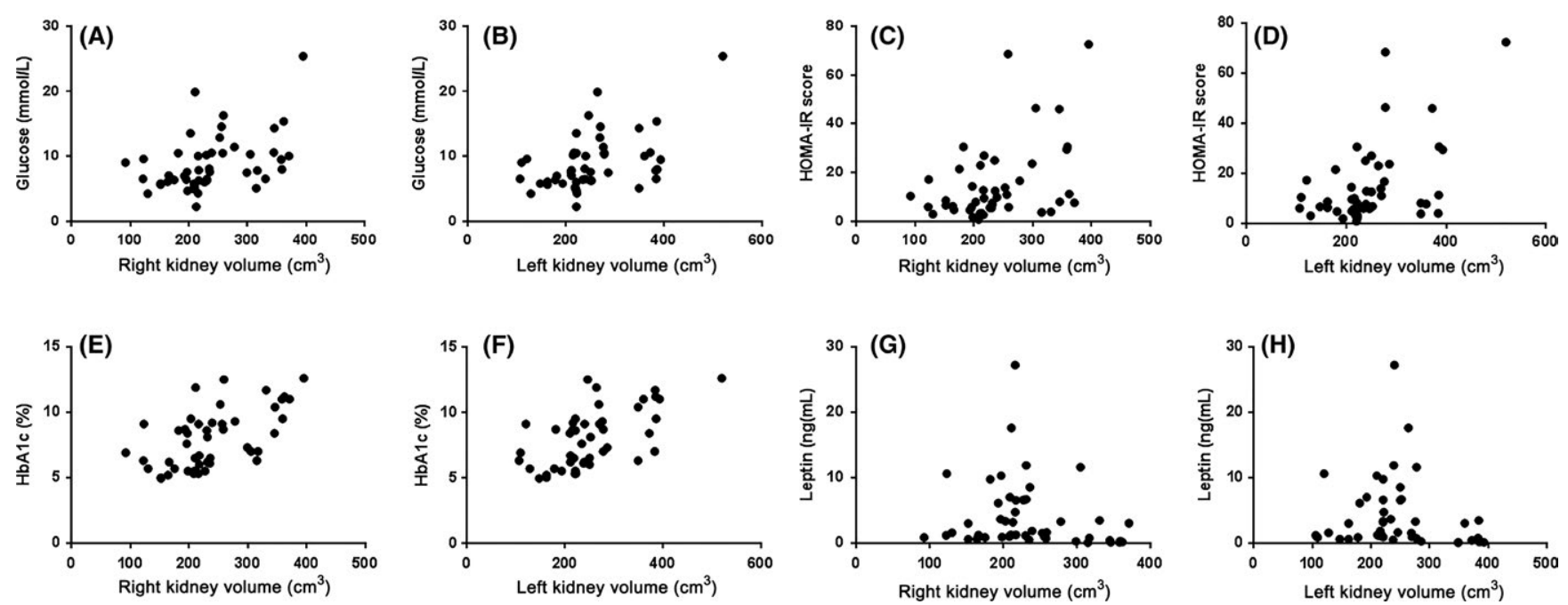

FIGURE 1 The association of kidney volume with metabolic parameters (1A, B: Glucose, 1C,D: HOMA-IR score, 1E,F: HbA1c, 1G, $\mathrm{H}$ : Leptin) 


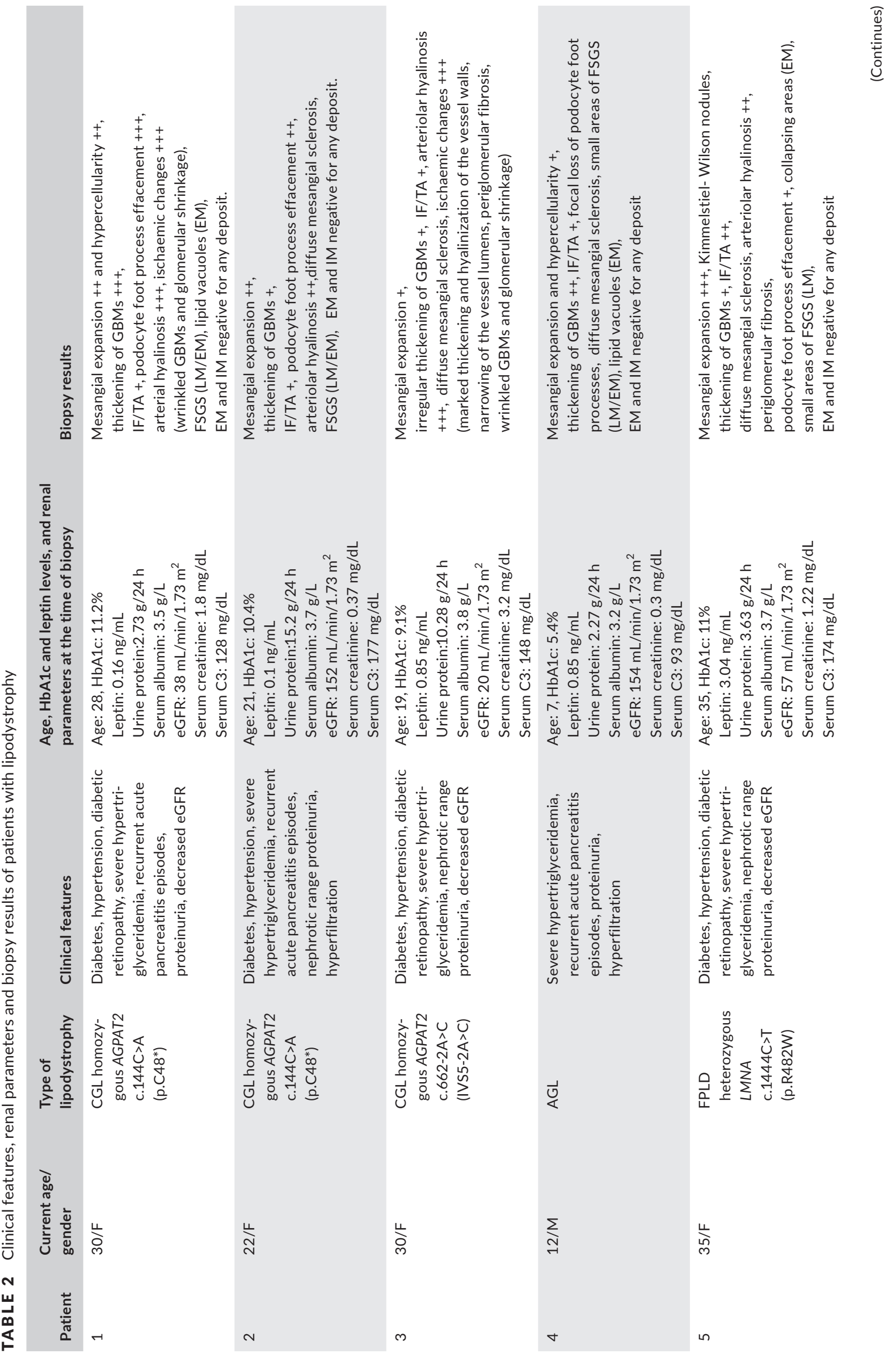



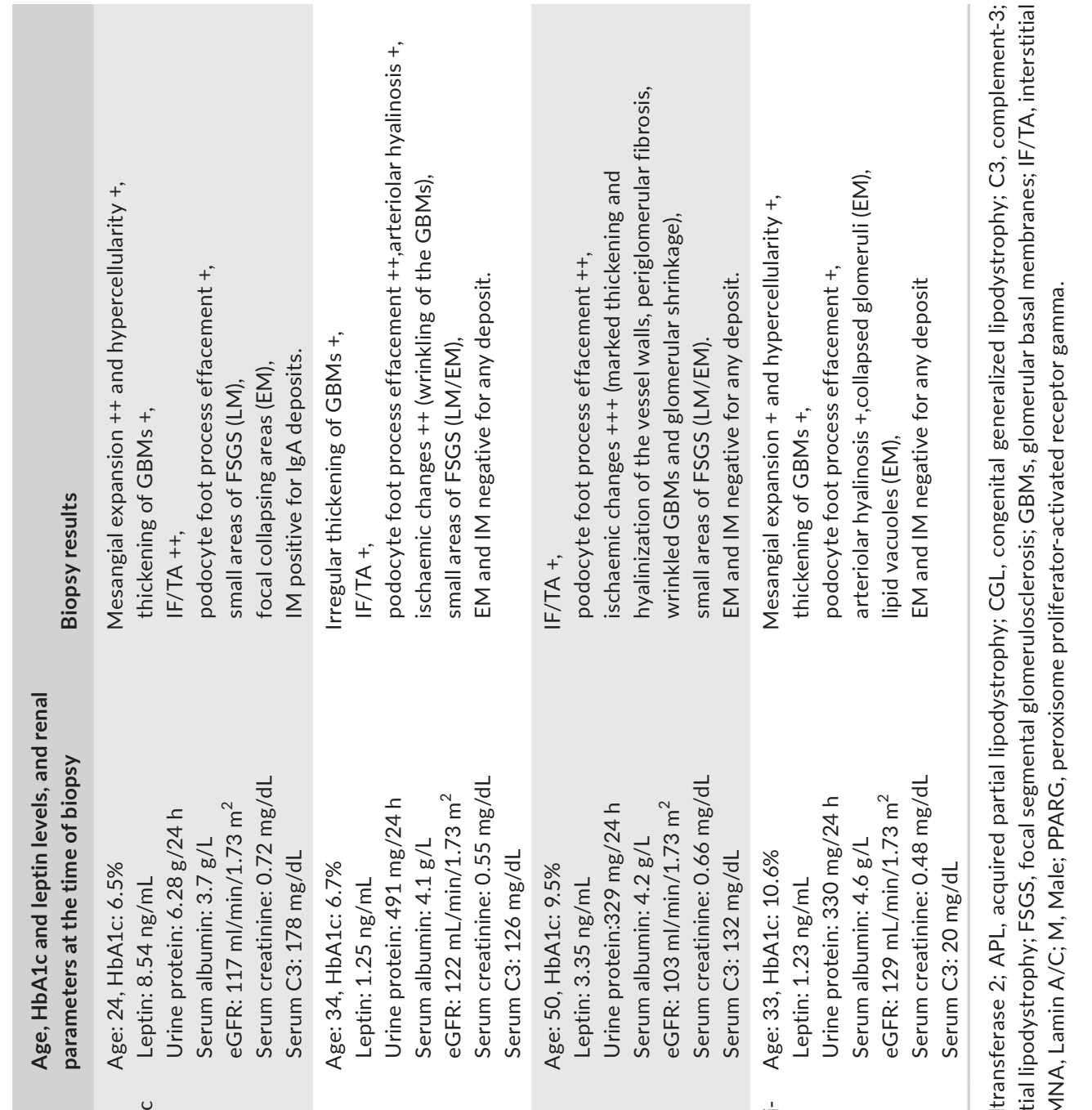

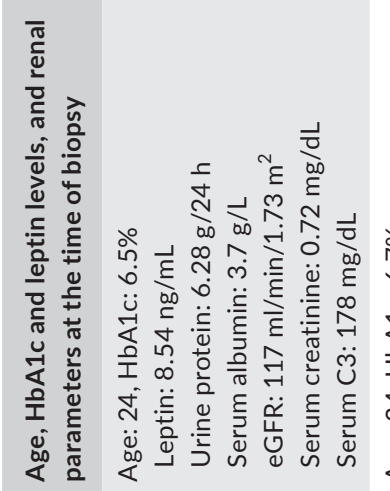

감

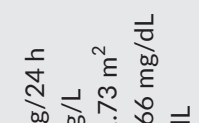

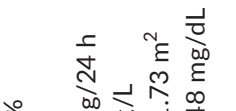
ㅇำ

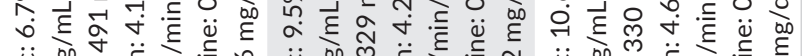

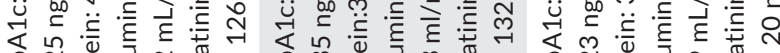
焉密

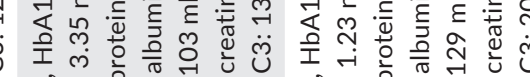

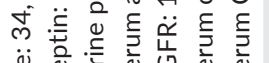

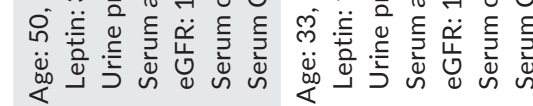
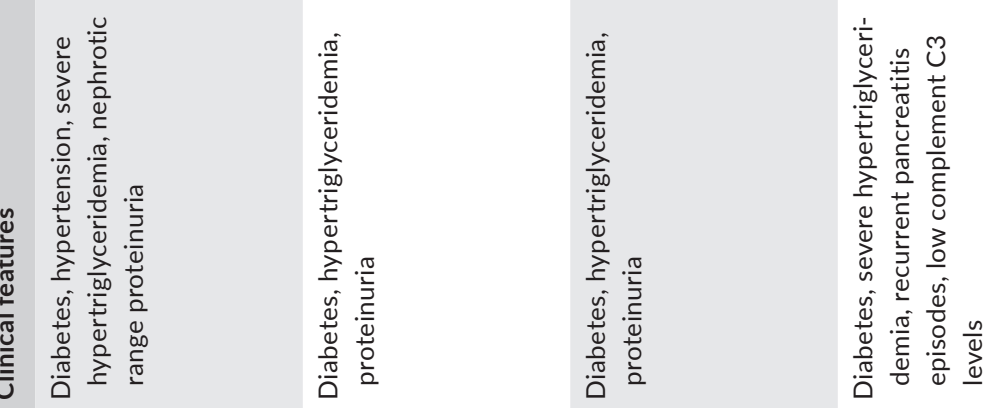

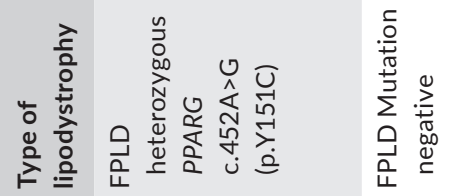

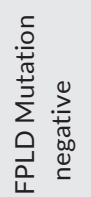

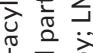

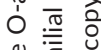

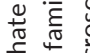

赛

응 문

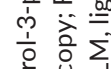

产.

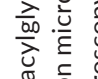

元

定造娄

袋出

蒙苋产

을 응
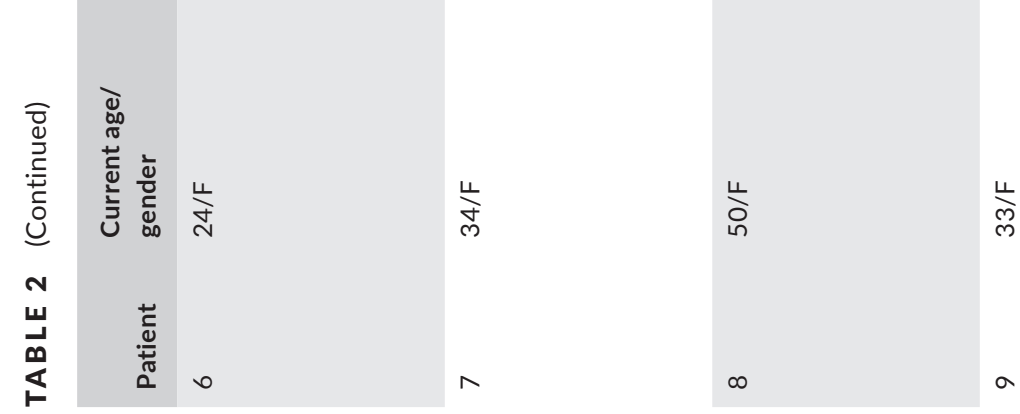

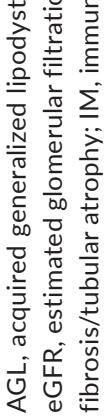


Table 2 summarizes the results of percutaneous renal biopsies and the clinical features of patients at the time of the biopsy. Renal biopsy was performed in 4 patients with generalized lipodystrophy (3 patients with CGL caused by AGPAT2 mutations and 1 patient with $\mathrm{AGL}$ ). Glomerular basal membranes (GBMs) were thickened in all patients with generalized lipodystrophy (Figure 2A). Mesangial expansion was remarkable (Figure $2 \mathrm{~B}$ ). Podocyte injury was obvious (Figure 2C). Areas of focal segmental sclerosis (FSGS) were observed (Figure 2B). Ischaemic changes were detected at various levels such as wrinkled GBMs and glomerular shrinkage (Figure 2D). Lipid vacuoles were visualized on EM images (Figure 2C). Renal biopsy was performed in 5 patients with partial lipodystrophy. Renal biopsy showed (Figure 2E) marked mesangial expansion with Kimmelstiel-Wilson nodules in a patient with FPLD caused by an LMNA pathogenic variant (R482W). GBMs were thickened. Ischaemic changes were remarkable. Podocyte injury and FSGS were detected (Figure 2F). Another biopsy from a patient with FPLD caused by a PPARG pathogenic variant revealed similar findings at different levels, but also IgA deposits in immunofluorescence microscopy which probably could be a coincidental pathology. Renal biopsy was performed in two sisters with mutation negative FPLD which showed ischaemic changes such as irregular thickening and wrinkling of the GBM, small areas of FSGS and podocyte foot process effacement. Renal biopsy was performed in a diabetic APL patient with low levels of circulating C3 which showed mesangial expansion and hypercellularity, thickening of GBMs and podocyte injury. Lipid vacuoles were visualized on EM images.

\section{DISCUSSION}

Although the kidney is one of the organs reported to be affected in the course of generalized lipodystrophy, the pathophysiology of renal damage has not been studied in a systematic fashion. In a previous study, Javor et $\mathrm{al}^{5}$ reported elevated urine albumin excretion in 22 of 25 (88\%) patients with generalized lipodystrophy, of those 15 (60\%) had macroalbuminuria and 5 (20\%) had nephrotic range proteinuria. Although proteinuria was also remarkably prevalent in our generalized lipodystrophy registry (35\% with macroalbuminuria and $14 \%$ with nephrotic range proteinuria), our observed range was significantly lower. This may be because some patients were very young or recently diagnosed with generalized lipodystrophy in our registry, while Javor et al $^{5}$ included patients with severe metabolic complications. In addition, the different lifestyle conditions and dietary factors may be modifying disease course and the severity of proteinuria. However, we should note that all patients with CGL older than 26 years were found to have CKD at some level in our registry.

Renal complications were also frequently detected in patients with partial lipodystrophy, although the age of onset was older than those with generalized lipodystrophy. Renal involvement has previously been reported in few patients with FPLD. Owen et $\mathrm{al}^{20}$ reported the first case of FPLD who developed mesangiocapillary glomerulonephritis type II without low circulating C3 levels. Later, several additional patients with FPLD and CKD were reported by different authors. ${ }^{6,7}$ Low levels of circulating C3 have been associated with CKD in patients with APL. ${ }^{3}$ Also in our registry, APL was associated with low levels of C3. As shown previously by our group, patients with APL may develop metabolic abnormalities associated with insulin resistance in the course of the disease ${ }^{21}$ although it remains unclear whether the insulin resistance in our small subset is modified by secondary environmental or genetic factors or primarily due to the underlying lipodystrophy.

A possible explanation for renal involvement may be longstanding poorly controlled diabetes in patients with lipodystrophy. The histopathologic features of diabetic nephropathy in humans are GBM thickening, podocytopenia, mesangial expansion, glomerular and arteriolar hyalinosis and Kimmelstiel-Wilson nodules. ${ }^{22}$ The loss of podocyte function, which contributes to the integrity of the glomerular filtration barrier, is a key event in the development of diabetic nephropathy. ${ }^{23}$ Hyperfiltration, which was detected in several patients in our study, is an early abnormality leading to diabetic nephropathy. ${ }^{24}$ However, we should note that formula-derived estimations are not always accurate in reflecting real renal function in patients with hyperfiltration or normal kidney functions. ${ }^{19}$ Ludtke et al $^{8}$ showed classical findings of diabetic nephropathy such as diffuse and nodular glomerulosclerosis (Kimmelstiel-Wilson lesions) and early ischaemic tubulopathy in a postmortem study. Javor et $\mathrm{al}^{5}$ mentioned an autopsy report which revealed diabetic nodular glomerulosclerosis in a patient with CGL. In another postmortem study, Hague et $\mathrm{al}^{25}$ described atherosclerotic vascular changes in kidneys. Histopathologically, most patients in our biopsy registry showed several characteristics of diabetic nephropathy such as GBM thickening, mesangial matrix abnormalities, podocyte injury and arterial hyalinosis although there were additional findings remarkable that could not be explained by diabetic nephropathy itself. Also, the lack of diabetic retinopathy in a significant number of patients suggests that additional mechanisms might play a role in the development of CKD in lipodystrophy.

Epidemiological studies have shown that obesity and metabolic syndrome are independent predictors of CKD, which suggests that renal abnormalities may develop long before the appearance of diabetes in patients with insulin resistance. ${ }^{26}$ Recently, several researchers described obesity-associated proteinuria which progresses to renal dysfunction that was associated with mesangial matrix expansion, glomerular hypertrophy and podocyte injury leading to the development of secondary FSGS. This specific type of FSGS was classified as an adaptive FSGS, which is thought to result from structural and functional adaptations which arise through mechanisms that place hemodynamic stress on an initially normal nephron population. ${ }^{27}$ FSGS was a remarkable finding in our biopsy specimens. FSGS has previously been reported in patients with lipodystrophy. ${ }^{4,5,28}$ One can assume that the pathogenesis of secondary FSGS, which is presumably due to the insulin resistance, might be somewhat common in obesity and lipodystrophy. FSGS may be secondarily mediated by structural-functional adaptations 
to glomerular hyperfiltration in these patients; however, cell autonomous mechanisms due to underlying genetic abnormalities such as the laminopathy cannot be ruled out. It may be possible that the laminopathy or other genetic defects may predispose the kidney cells to cellular injury and the glomerulosclerosis may be the end-stage progression of cellular damage.

Limited storage capacity of adipose tissue in lipodystrophy results in spillover of dietary and endogenously synthesized triglycerides or other lipids into ectopic sites such as liver which leads to severe insulin resistance. ${ }^{29}$ The presence of ectopic lipid vacuoles in the biopsy specimen from our patients provides evidence on ectopic accumulation of triglycerides or other lipids in kidney; however, the potential association of ectopic renal lipid accumulation and renal complications remains unclear. Recent evidence suggests that ectopic renal lipid accumulation may be associated with kidney dysfunction. ${ }^{26,30}$ Studies have demonstrated that ectopic accumulation of lipids in the kidney results in increased expression of sterol regulatory element binding protein (SREBP-1), a key transcription factor in lipogenesis, in obesity prone mice fed a high-fat diet. These mice, in turn, developed glomerulosclerosis and proteinuria. Also, transgenic overexpression of SREBP-1 in mice promoted renal injury driven by ectopic lipid accumulation. In contrast, mice lacking SREBP-1 were protected from renal injury when they were challenged on high-fat diet. $^{31,32}$

Javor et $\mathrm{al}^{5}$ reported a significant decrease in proteinuria and normalization of creatinine clearance in patients with generalized lipodystrophy treated with metreleptin. Ebihara et $\mathrm{al}^{33}$ reported a decrease in urinary albumin excretion in 4 Japanese patients with generalized lipodystrophy treated with metreleptin. A significant reduction in the creatinine clearance of 5 patients with glomerular hyperfiltration was also reported in the same study. Later, Chong et $\mathrm{al}^{34}$ reported a $51 \%$ reduction in 24 -hour urinary protein excretion of generalized lipodystrophy patients when they were treated with metreleptin for one year. Very recently, a report from our group described the first patient treated with metreleptin for generalized lipodystrophy in Turkey, which resulted in a significant improvement in glycaemic control and lipid profile, and also a significant reduction in urinary protein excretion. ${ }^{35}$ While it is reasonable to assume that metreleptin treatment may have a positive impact on the progression of kidney disease in patients with lipodystrophy, the data presented for approval of metreleptin in the USA included a number of patients in whom the kidney disease progressed to ESRD while being treated with metreleptin. All of these patients had evidence of reduced GFR at the time of
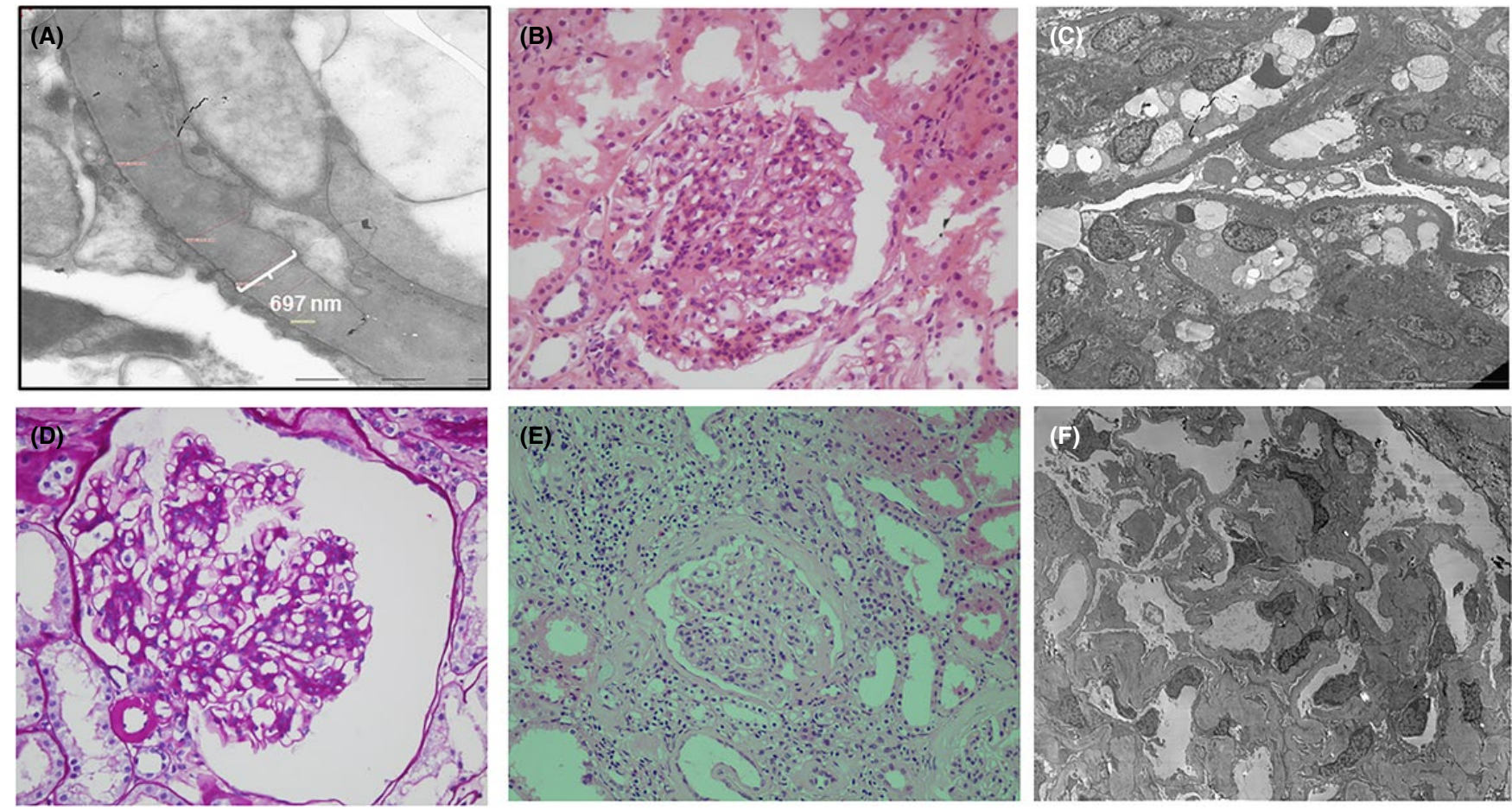

FIG URE 2 Renal biopsies performed in patients with lipodystrophy. A, EM image ( $\times 6300$, patient- 1 ) shows thickening of the GBMs (measured ranging from $587 \mathrm{~nm}$ to $1333 \mathrm{~nm}$ at different areas). B, LM image (HE ×40, patient-1) shows mesangial expansion and hypercellularity. Small arteries and arterioles show hyaline thickening. Small area of FSGS is noted. C, EM image $(\times 500$, patient-1) shows podocyte foot process effacement, suggestive of podocyte injury. Lipid vacuoles are visible which suggest ectopic lipid accumulation. No electron dense deposit is detected. D, LM image (PAS $\times 40$, patient-1) shows ischaemic changes at various levels such as wrinkled GBMs and glomerular shrinkage. E, LM image (HE $\times 20$, patient-5) shows mesangial expansion, thickening of GBMs, periglomerular fibrosis, segmental sclerosis and Kimmelsteil-Wilson nodules. F, EM image $(\times 1000$, patient-5) shows widespread areas of podocyte foot process effacement and of collapse [Colour figure can be viewed at wileyonlinelibrary.com] 
initiation of metreleptin. Therefore, the exact role of metreleptin in the prevention of renal disease associated with lipodystrophy is still not well understood and treatment of patients with reduced GFR should be undertaken with extreme caution and close follow-up. The current approval package does state the progression of chronic kidney disease as a potentially possible adverse event of therapy. The impact of the newer treatment strategies on the disease course will have to be evaluated separately; however, recognition of the kidney disease in the natural history of the disease is vitally important not only for the clinicians following these patients but also for both drug developers and regulatory agencies.

In conclusion, renal complications are quite common in lipodystrophy syndromes. The kidney involvement is clinically characterized by proteinuria that can progress to nephrotic syndrome and eventually to renal failure. Patients with generalized lipodystrophy are at the highest risk as the onset of renal complications can be early. Renal involvement appears to be multifactorial and may at least be driven by either poorly controlled diabetes and/or the underlying severe insulin resistance. Also, ectopic lipid accumulation or specific genetic mechanisms can potentially play a role; however, further studies are needed to clarify the specific contributions of each of these factors to the chronic kidney disease of these syndromes.

\section{ACKNOWLEDGEMENTS}

We thank the patients and families for volunteering in our studies as well as referring physicians. This work was funded by the TuLip. EAO was partially supported by National Institutes of Health (NIH) grant RO-1DK88114.

\section{CONFLICT OF INTERESTS}

B.A., H.O., S.O., T.D. and T.A. have attended Scientific Advisory Board Meetings organized by Aegerion Pharmaceuticals. B.A. has received honoraria as speaker from AstraZeneca, Lilly, MSD, Novartis, Novo Nordisk, Boehringer-llgenheim, Servier and Sanofi-Aventis. E.A.O. reports the following conflicts: Grant support: Aegerion Pharmaceuticals, Ionis Pharmaceuticals, Akcea Therapeutics, Gemphire (current), GI Dynamics, AstraZeneca (past 2 years). Consultant or Advisor: AstraZeneca, BMS (Past), Thera Therapeutics, Regeneron, Aegerion (current). Drug support: Aegerion Pharmaceuticals, Akcea Therapeutics, Rhythm Pharmaceuticals. Other support: Boehringer Ingelheim (past two years), Aegerion Pharmaceuticals (current). Other authors have nothing to disclose. The authors declare that they have no competing financial interests.

\section{ORCID}

Baris Akinci iD http://orcid.org/0000-0002-8634-4845

Basak Ozgen Saydam (iD http://orcid.org/0000-0001-9457-8919

Banu Sarer Yurekli iD http://orcid.org/0000-0003-1809-2655

\section{REFERENCES}

1. Patni N, Garg A. Congenital generalized lipodystrophies-new insights into metabolic dysfunction. Nat Rev Endocrinol. 2015; 11:522-534

2. Peters JM, Barnes R, Bennett L, Gitomer WM, Bowcock AM, Garg A. Localization of the gene for familial partial lipodystrophy (Dunnigan variety) to chromosome 1q21-22. Nat Genet. 1998;18:292-295.

3. Misra A, Peethambaram A, Garg A. Clinical features and metabolic and autoimmune derangements in acquired partial lipodystrophy: report of 35 cases and review of the literature. Medicine (Baltimore). 2004;83:18-34.

4. Musso C, Javor E, Cochran E, Balow JE, Gorden P. Spectrum of renal diseases associated with extreme forms of insulin resistance. Clin J Am Soc Nephrol. 2006;1:616-622.

5. Javor ED, Moran SA, Young JR, et al. Proteinuric nephropathy in acquired and congenital generalized lipodystrophy: baseline characteristics and course during recombinant leptin therapy. J Clin Endocrinol Metab. 2004;89:3199-3207.

6. Imachi H, Murao K, Ohtsuka S, et al. A case of Dunnigan-type familial partial lipodystrophy (FPLD) due to lamin A/C (LMNA) mutations complicated by end-stage renal disease. Endocrine. 2009;35:18-21.

7. Klupa T, Szopa M, Skupien J, et al. LMNA gene mutation search in Polish patients: new features of the heterozygous Arg482GIn mutation phenotype. Endocrine. 2009;36:518-523.

8. Ludtke A, Roos GM, van Hettinga M, Horst BA, Worman HJ, Schmidt HH. Post-mortem findings in Dunnigan-type familial partial lipodystrophy. Diabet Med. 2010;27:245-246.

9. American Diabetes Association. Standards of medical care in diabetes-2014. Diabetes Care 2014;37(Suppl 1):S14-S80.

10. Expert Panel on Detection, Evaluation, And Treatment of High Blood Cholesterol In Adults. Executive Summary of The Third Report of The National Cholesterol Education Program (NCEP) Expert Panel on Detection, Evaluation, And Treatment of High Blood Cholesterol In Adults (Adult Treatment Panel III). JAMA. 2001;285:2486-2497.

11. Expert Panel on Integrated Guidelines for Cardiovascular Health and Risk Reduction in Children and Adolescents, National Heart, Lung, and Blood Institute. Expert panel on integrated guidelines for cardiovascular health and risk reduction in children and adolescents: summary report. Pediatrics 2011; 128(Suppl 5):S213-S256.

12. Levey AS, Stevens LA, Schmid CH, et al. A new equation to estimate glomerular filtration rate. Ann Intern Med. 2009;150:604-612.

13. Schwartz GJ, Work DF. Measurement and estimation of GFR in children and adolescents. Clin J Am Soc Nephrol. 2009;4:1832-1843.

14. Stevens PE, Levin A. Evaluation and management of chronic kidney disease: synopsis of the kidney disease: improving global outcomes 2012 clinical practice guideline. Ann Intern Med. 2013;158:825-830.

15. Hogg RJ, Portman RJ, Milliner D, Lemley KV, Eddy A, Ingelfinger J. Evaluation and management of proteinuria and nephrotic syndrome in children: recommendations from a pediatric nephrology panel established at the National Kidney Foundation conference on proteinuria, albuminuria, risk, assessment, detection, and elimination (PARADE). Pediatrics. 2000;105:1242-1249.

16. Cheong B, Muthupillai R, Rubin MF, Flamm SD. Normal values for renal length and volume as measured by magnetic resonance imaging. Clin J Am Soc Nephrol. 2007;2:38-45.

17. Akinci B, Onay H, Demir T, et al. Natural history of congenital generalized lipodystrophy: a nationwide study from Turkey. J Clin Endocrinol Metab. 2016;101:2759-2767.

18. Akinci B, Onay H, Demir T, et al. Clinical presentations, metabolic abnormalities and end-organ complications in patients with familial partial lipodystrophy. Metabolism. 2017;72:109-119.

19. Gross JL, de Azevedo MJ, Silveiro SP, Canani LH, Caramori ML, Zelmanovitz T. Diabetic nephropathy: diagnosis, prevention, and treatment. Diabetes Care. 2005;28:164-176. 
20. Owen KR, Donohoe M, Ellard S, et al. Mesangiocapillary glomerulonephritis type 2 associated with familial partial lipodystrophy (DunniganKobberling syndrome). Nephron Clin Pract. 2004;96:c35-c38.

21. Akinci B, Koseoglu FD, Onay H, et al. Acquired partial lipodystrophy is associated with increased risk for developing metabolic abnormalities. Metabolism. 2015;64:1086-1095.

22. Artunc F, Schleicher E, Weigert C, Fritsche A, Stefan N, Häring HU. The impact of insulin resistance on the kidney and vasculature. Nat Rev Nephrol. 2016;12:721-737.

23. Diez-Sampedro A, Lenz O, Fornoni A. Podocytopathy in diabetes: a metabolic and endocrine disorder. Am J Kidney Dis. 2011;58:637-646.

24. Jerums G, Premaratne E, Panagiotopoulos S, Maclsaac RJ. The clinical significance of hyperfiltration in diabetes. Diabetologia. 2010;53:2093-2104.

25. Haque WA, Vuitch F, Garg A. Post-mortem findings in familial partial lipodystrophy Dunnigan variety. Diabet Med. 2002;19:1022-1025.

26. Guebre-Egziabher F, Alix PM, Koppe L, et al. Ectopic lipid accumulation: a potential cause for metabolic disturbances and a contributor to the alteration of kidney function. Biochimie. 2013;95:1971-1979.

27. Kambham N, Markowitz GS, Valeri AM, Lin J, D'Agati VD. Obesityrelated glomerulopathy: an emerging epidemic. Kidney Int. 2001; 59:1498-1509.

28. Thong KM, Xu Y, Cook J, et al. Cosegregation of focal segmental glomerulosclerosis in a family with familial partial lipodystrophy due to a mutation in LMNA. Nephron Clin Pract. 2013;124:31-37.

29. Ertunc ME, Hotamisligil GS. Lipid signaling and lipotoxicity in metaflammation: indications for metabolic disease pathogenesis and treatment. J Lipid Res. 2016;57:2099-2114.

30. D'Agati VD, Chagnac A, de Vries AP, et al. Obesity-related glomerulopathy: clinical and pathologic characteristics and pathogenesis. Nat Rev Nephrol. 2016;12:453-471.

31. Sun L, Halaihel N, Zhang W, Rogers T, Levi M. Role of sterol regulatory element-binding protein 1 in regulation of renal lipid metabolism and glomerulosclerosis in diabetes mellitus. J Biol Chem. 2002;277:18919-18927.

32. Jiang T, Wang Z, Proctor G, et al. Diet-induced obesity in C57BL/6J mice causes increased renal lipid accumulation and glomerulosclerosis via a sterol regulatory element-binding protein-1c-dependent pathway. J Biol Chem. 2005;280:32317-32325.

33. Ebihara K, Kusakabe T, Hirata M, et al. Efficacy and safety of leptinreplacement therapy and possible mechanisms of leptin actions in patients with generalized lipodystrophy. J Clin Endocrinol Metab. 2007;92:532-541.

34. Chong AY, Lupsa BC, Cochran EK, Gorden P. Efficacy of leptin therapy in the different forms of human lipodystrophy. Diabetologia. 2010;53:27-35.

35. Simsir IY, Yurekli BS, Saygili F, Altay C, Akinci B. First metreleptin treatment for generalized lipodystrophy in Turkey. Diabetes Obes Metab. 2017;19:299-301.

\section{SUPPORTING INFORMATION}

Additional supporting information may be found online in the Supporting Information section at the end of the article.

How to cite this article: Akinci B, Unlu SM, Celik A, et al. Renal complications of lipodystrophy: A closer look at the natural history of kidney disease. Clin Endocrinol (Oxf). 2018;89:65-75. https://doi.org/10.1111/cen.13732 